\title{
PRESENTACIÓN AL NÚMERO 18
}

Tengo el placer de presentar, por primera vez, un número de la Revista REJIE, Nueva Época, oportunidad que me brinda la profesora González Ríos, Directora de la Revista, y a quien quiero agradecer su confianza en esta nueva responsabilidad que asumo. Quiero aprovechar también estas primeras palabras para dar la bienvenida a la profesora Castro López que se incorpora a este equipo de trabajo y asume la meticulosa y gratificante tarea de la secretaría de la Revista.

En el número 18 de la REJIE publicamos un total de seis artículos y dos recensiones. El apartado de Innovación educativa y metodologías docentes se abre con un interesante artículo de la profesora Canto López, Lecturer in Law de la University of Leicester (UK), que aborda los cambios que recientemente se han producido en el ordenamiento jurídico británico en el ámbito general de la educación universitaria y en el particular de la educación jurídica. Se analiza el Teaching Excellence Framework (TEF) como nuevo marco de excelencia universitaria que pretende mejorar el estándar de la educación superior y al mismo tiempo dar publicidad a aquellas Universidades con el nivel de calidad más alto. Completando lo anterior se analiza el marco jurídico del Solicitors Qualifying Examination (SQE) que es el nuevo examen capacitador para los solicitors.

El segundo artículo lo ha realizado la Dra. Soto Moya de la Universidad de Málaga, y en él se presenta una metodología docente denominada flipped classroom o clase invertida que consiste en emplear el tiempo fuera del aula en realizar determinados procesos de aprendizaje que tradicionalmente se hacen dentro de la misma y, por su parte, dentro del aula, con la presencia, guía y experiencia del docente, el tiempo se emplea en potenciar y facilitar otros procesos de adquisición y práctica de conocimientos, en aplicar conceptos y participar de forma creativa en los contenidos. La autora destaca que esta metodología es especialmente oportuna para asignaturas como el Derecho Financiero y Tributario que tiene una gran virtualidad práctica.

El tercer artículo, elaborado por la profesora Zumaquero Gil, Profesora Contratada Doctora de la Universidad de Málaga, expone una experiencia docente llevada a cabo en la asignatura Introducción al Derecho del Grado en Turismo. El artículo explica el diseño y puesta en marcha de un sistema de prácticas, que incluye la técnica de los juegos de rol para motivar la participación de los alumnos en su proceso de aprendizaje y mejorar competencias como la capacidad de argumentación jurídica, la capacidad de análisis o síntesis y el trabajo en equipo. A modo de conclusión se expone el sistema de evaluación y la valoración de los resultados tanto por los alumnos como por el docente. 
El cuarto de los artículos nos presenta una investigación realizada en Cuba sobre las estrategias pedagógicas para una mejor enseñanza de estudios superiores en Derecho a estudiantes "mayores". La autora, Diana Hernández de la Guardia, profesora e investigadora auxiliar del Centro de Investigaciones Jurídicas de Cuba, argumenta el reto que supone para los docentes la asunción de docencia teniendo como destinatarios un público de estudiantes "mayores" y nos aporta un conjunto de técnicas y métodos adaptados a las particularidades de estos estudiantes que demandan una concepción holística de la enseñanza.

Nuestros estudios de investigación sustantiva se abren con el artículo de José Alberto España Pérez, Doctorando en Ciencias Jurídicas y Sociales, que aborda el régimen jurídico de la homologación de los títulos universitarios obtenidos en instituciones extranjeras o en centros españoles adscritos a un programa foráneo y que se encuentra actualmente regulado por el Real Decreto 967/2014, de 21 de noviembre. El autor profundiza en los dos procedimientos bien diferenciados que se articulan en la norma citada: de un lado, el procedimiento para la homologación, declaración de equivalencia a titulación y a nivel académico universitario oficial y para la convalidación de estudios extranjeros de educación superior; de otro lado, el procedimiento para determinar la correspondencia a los niveles del marco español de cualificaciones para la educación superior de los títulos oficiales de Arquitecto, Ingeniero, Licenciado, Arquitecto Técnico, Ingeniero Técnico y Diplomado.

El artículo que cierra el presente número ha sido realizado por las profesoras de Derecho Procesal de la Universidad de Santiago de Compostela Almudena Valiño Ces y Cristina Alonso Salgado. En él se estudia la figura del acuerdo extrajudicial de pagos, como medida de mediación concursal, incorporada a nuestro ordenamiento por la modificación de la Ley de emprendedores, a través del Real Decreto-Ley 1/2015, de 27 de febrero. Las autoras examinan con detalle en su trabajo la forma en que se ha regulado para concluir si merece o no la calificación de "mediación" y si realmente la incorporación de esta figura supone un avance de nuestro ordenamiento jurídico.

Como colofón, incluimos las reseñas de los libros: Servicio de interés general y protección de los usuarios (educación, sanidad, servicios sociales, vivienda, energía, transportes y comunicaciones telefónicas), de González Ríos, y Justicia relacional y principio de fraternidad, de Márquez Prieto, que aborda un tema novedoso y de profundas raíces humanistas y jurídicas escasamente tratado en la doctrina científica.

Carmen María Ávila Rodríguez

Subdirectora académica de la REJIE, Nueva época 